\title{
Cardiovascular and Cerebrovascular Problems in the Development of Cognitive Impairment: For Medical Professionals Involved in the Treatment of Atherosclerosis
}

\author{
Michihiro Suwa \\ Department of Cardiology, \\ Hokusetsu General Hospital, Takatsuki, Osaka, \\ Japan
}

\section{Introduction}

When cognitive function declines at a rate greater than that expected based on the actual age, life circumstances and educational level, we define it as cognitive impairment (Blennow et al., 2006; Gauthier et al 2006). In the older generation, the neurodegenerative process is considered to occur several years before the development of clinically detectable cognitive impairment. Although aging is the most clear factor in the development of this disease process, several epidemiological studies have elucidated that cardiovascular risk factors, i.e., hyperlipidemia, hypertension, smoking and diabetes, are also associated with cerebrovascular disease processes that may deteriorate cognitive function and advance dementia (Casserly \& Topol, 2004; Nash \& Fillit, 2006; Whitmer et al., 2005). In this chapter, I would like to introduce the current positioning of cognitive impairment as a consequence of cardiovascular diseases as well as a form of cerebrovascular disease, to neurologists or psychiatrists as well as to general physicians or cardiologists.

\section{Cognitive impairment}

Currently, Alzheimer's disease is the most common form of dementia or cognitive impairment, but less than $20 \%$ of dementia patients exhibit the isolated form of Alzheimer's disease and around $50 \%$ of such patients exhibit a combination of Alzheimer's disease and intracerebral vascular disease. By contrast, the isolated vascular type only contributes $20 \%$ (Meguro et al., 2002). Therefore, various problems related to metabolic syndrome, i.e., hypertension, hyperlipidemia, diabetes, and smoking habit, contribute to the development or deterioration of cognitive impairment.

\section{Cardiovascular problems in cognitive impairment}

Furthermore, recent investigations have suggested that the incidence of cognitive impairment is higher in patients with congestive heart failure and that treatment for left ventricular (LV) systolic dysfunction may prevent or delay the development of dementia in 
elderly patients (Zuccala et al., 2003, 2005). An Italian investigation indicated that the incidence of congestive heart failure was markedly higher in subjects with Mini-Mental State Examination (MMSE) scores <24 (20.2\%), compared with those with scores $\geq 24(4.6 \%)$ (Zuccala et al., 2003). Also, the presence of cognitive impairment has been associated with increased in-hospital mortality in older patients with heart failure (Zuccala et al., 2005). These data may indicate that low cardiac output due to heart failure is related to the deterioration of cognitive function, although there have been no reports regarding the pathophysiology or etiology of heart failure in relation to cognitive impairment. Another investigation indicated an independent relation between the levels of b-type natriuretic peptide (BNP) and the degree of cognitive impairment in older subjects (>55years of age) with cardiovascular disease; despite the fact that the mechanism was unclear (Gunstad et al., 2006).

In patients with heart failure, more than half of them, especially in females, showed normal or preserved LV ejection fraction (EF), i.e., exhibited heart failure resulting from LV diastolic dysfunction (Hogg et al. ,2004). Also, in heart failure patients with cardiovascular risk factors, i.e., hyperlipidemia, hypertension, smoking and diabetes, heart failure with preserved EF is also common. Therefore, we evaluated the relationship between LV diastolic dysfunction and cognitive impairment in Japanese patients with cardiovascular diseases (Suwa \& Ito, 2009).

In our study, patients were divided into 2 groups; those patients with normal cognitive function or mild cognitive impairment (MMSE $>=24 ; n=68$ : group $N$ ) and those with depressed cognitive function (MMSE $<24, \mathrm{n}=13$ ). Diastolic function was evaluated based upon the ratio of the early diastolic mitral flow velocity (E) by pulse-wave Doppler echocardiography to the early diastolic mitral annular myocardial velocity (e') by tissue Doppler echocardiography (Diastolic Doppler index: E/e'). BNP was also evaluated as an index of heart failure. Consequently, in depressed cognitive function, diastolic Doppler index, E/e', was deteriorated $(6.1 \pm 1.3$ vs. $\mathrm{N}: 4.6 \pm 1.3, \mathrm{p}<0.0003)$ and $\mathrm{BNP}$ was higher $(137 \pm 142 \mathrm{pg} / \mathrm{ml}$ vs. $\mathrm{N}: 60 \pm 49 \mathrm{pg} / \mathrm{ml}, \mathrm{p}<0.007)$, compared with those with normal cognitive function. Furthermore, the number of patients with diabetes was also higher in depressed cognitive function than in normal cognitive function (46\% vs. N: $18 \%$ ). From these studies evaluating the relation between cardiac and cognitive function, heart failure due to LV systolic and diastolic dysfunction can affect the development and the deterioration of cognitive impairment.

Poor cerebral circulation:

Left ventricular systolic dysfunction

Left ventricular diastolic dysfunction

Stroke:

Atrial fibrillation, Atherosclerotic vascular

Deep white matter hyperintensity diseases including of carotid artery stenosis in brain MRI: Atherosclerotic abnormalities, due to hypertension, diabetes, hyperlipidemia, and smoking

Hippocampal atrophy in brain: Senile process

MRI: magnetic resonance imaging

Table 1. Relationship between cardiovascular abnormalities and cerebrovascular diseases affecting the decline of cognitive function 
The occurrence of atrial fibrillation (AF) is a risk of stroke, and stroke increases the risk of cognitive decline and dementia. Therefore, AF has been reported to be associated with cognitive decline and dementia (Jozwiak et al., 2006). Recently, even in stroke-free patients it has been shown that AF is a risk for cognitive impairment and hippocampal atrophy (Knecht et al., 2008). For these reasons, it was considered that AF was associated with abnormalities of hemostasis, endothelial damage, platelet dysfunction, and low cardiac output.

As another measurable index in the vascular system, the ankle to brachial index is also related to incidence of total dementia, vascular dementia and Alzheimer's disease, especially in carriers of the apolipoprotein E gene abnormality (Laurin et al. 2007).

\section{Common interest between cardiovascular and cerebrovascular diseases}

Brain magnetic resonance imaging is conducted to screen for cerebrovascular disease as well as cerebral disease, and hyperintensities in the deep white matter on T2-weighted images can be incidentally detected in $10-20 \%$ in adults aged 64 to $94 \%$ at age 82 in the general population (Fig.1 and Fig.2). At present, these white matter lesions are related to chronic hypoperfusion and disruption of the blood brain barrier due to small vessel disease in the lesion area (Debette \& Markus, 2010). Also, white matter hyperintensities are more common in patients with cerebrovascular disease as well as cardiovascular disease, with risk factors affecting atherosclerosis, inclusive of hypertension (Hajjar et al., 2011). Furthermore, metaanalysis reveals that the white matter lesions predict an increased risk of stroke, dementia, and death. Although data that treatment for these risk factors reduces the progression of white matter hyperintensities are limited, it is also reported that antihypertensive therapy reduced the progression in patients with stroke (Saxby et al., 2008). Therefore, white matter hyperintensities may be important markers to not only detect the risk of stroke and dementia but also diagnose the atherosclerosis in cerebro-cervical vascular system. The progression of white matter lesions is independently related to baseline cerebral lesion, higher age, hypertension, and current smoking. Also, atherosclerotic processes in the carotid artery, connecting to the cerebral artery, are associated with the cerebral small vessel disease (Romero et al., 2009).

Modified Mini-Mental State Examination scale falls more according to the worsening of white matter grade (prominently in grade Two +). (Fig.3. Longstreth et al. 2005) (with permission, License No.2776831264727)

To date, some angiotensin receptor blockers have been reported to significantly reduce the incidence and progression of Alzheimer's disease and dementia, compared with the use of angiotensin converting enzyme inhibitors or other cardiovascular drugs, in a predominant male population (Saxby et al., 2008). Therefore, when prescribing antihypertensive drugs we may have to consider the contribution of such medicines.

At present, the CHADS2 score is widely used to validate the risk for stroke in patients with AF. A newer clinical study has shown that the CHADS2 score is useful to predict ischemic stroke in patients with stable coronary artery disease, even in those without baseline atrial fibrillation (Welles et al., 2011) 

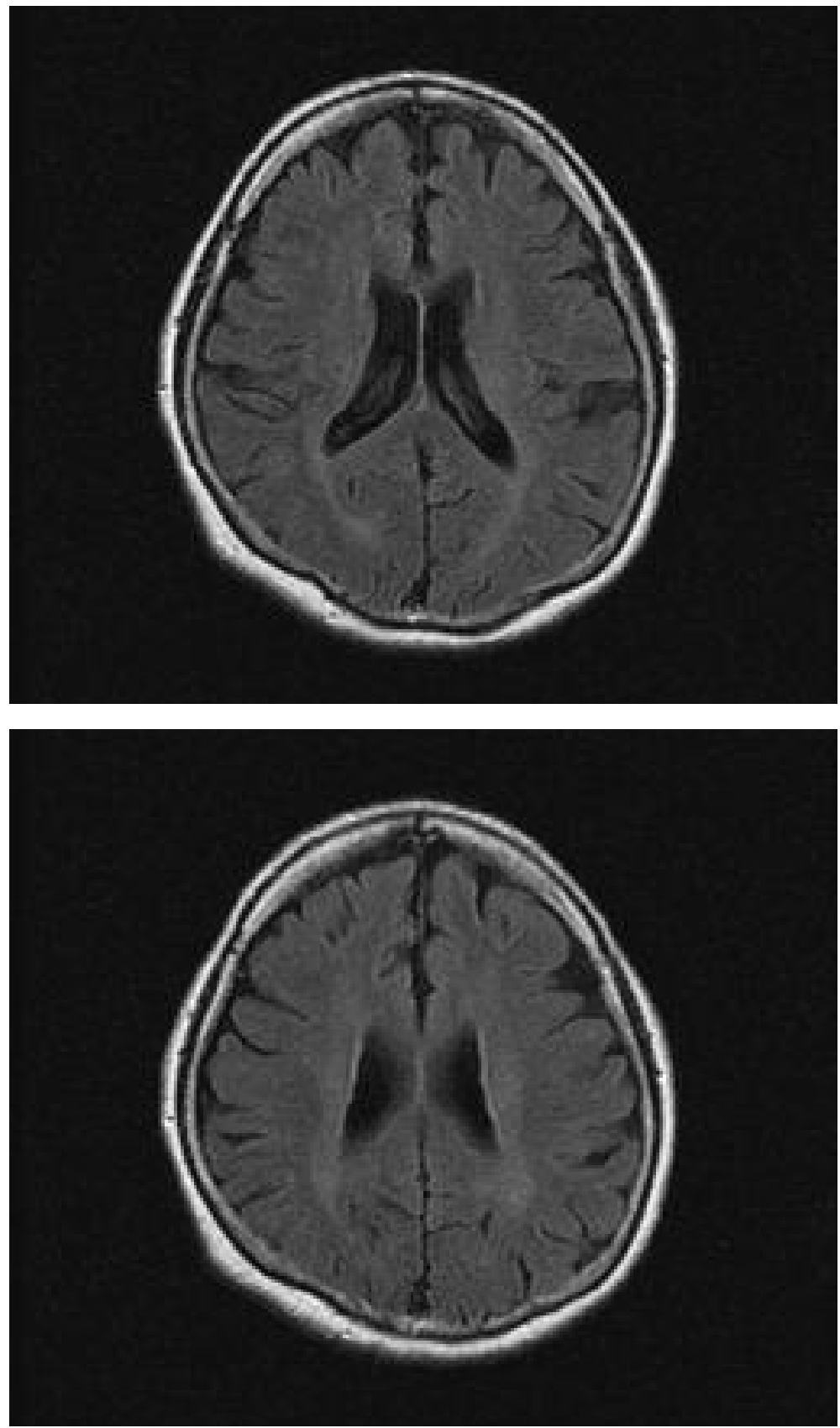

Fig. 1. Brain magnetic resonance imaging on $\mathrm{T} 2$ weighted images obtained from a 77 year old female without cognitive impairment and being under medication for hypertension. These images show somewhat brain atrophy but no white matter hyperintensities. 
Cardiovascular and Cerebrovascular Problems in the Development of
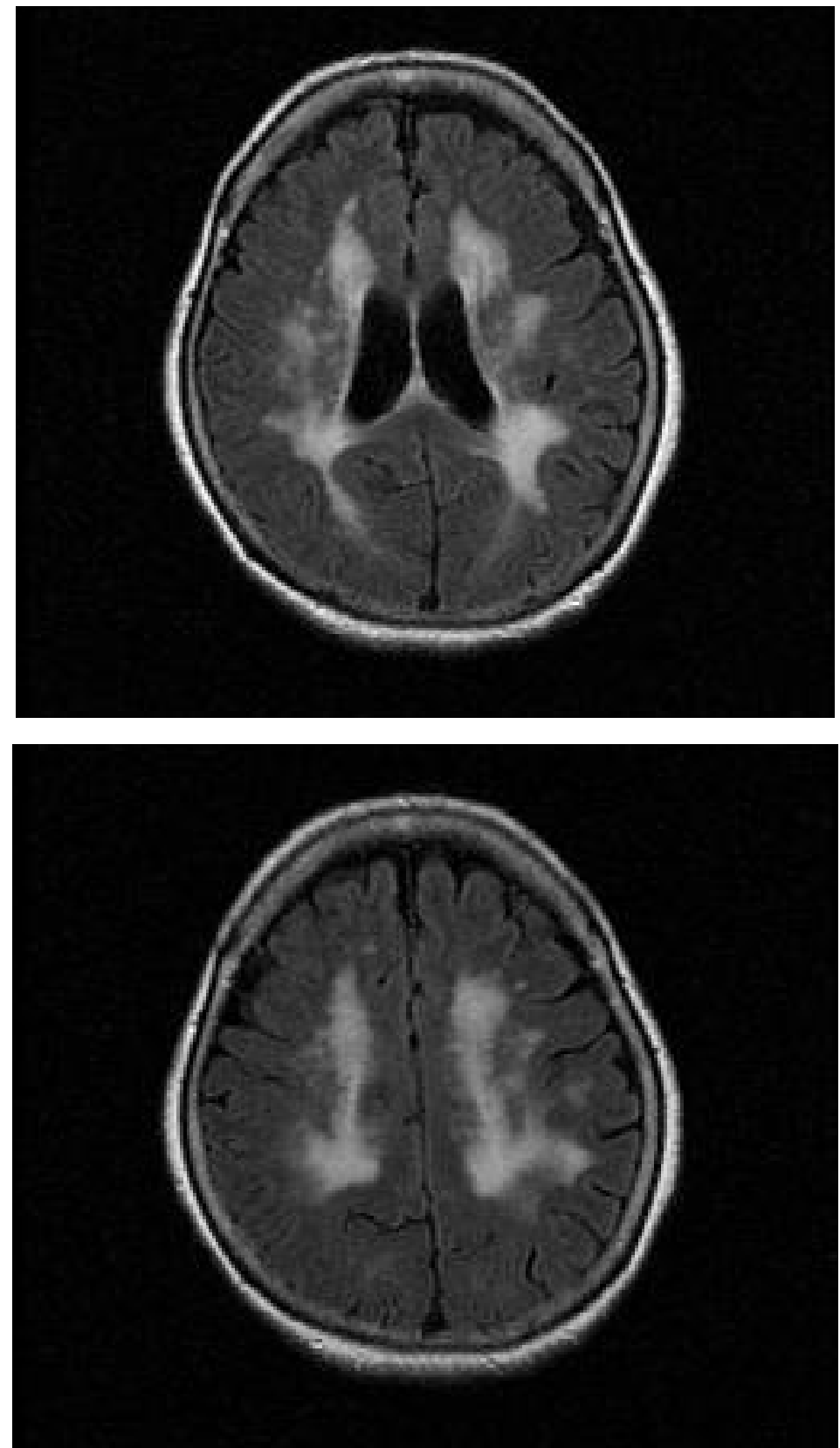

Fig. 2. White matter hyperintensities on brain magnetic resonance imaging from a 73 year old female with advanced cognitive impairment (score 18 on MMSE). Extensive hyperintensities can be seen in deep white matter, especially in periventricular region. She is under medication for hypertension and hyperlipidemia 


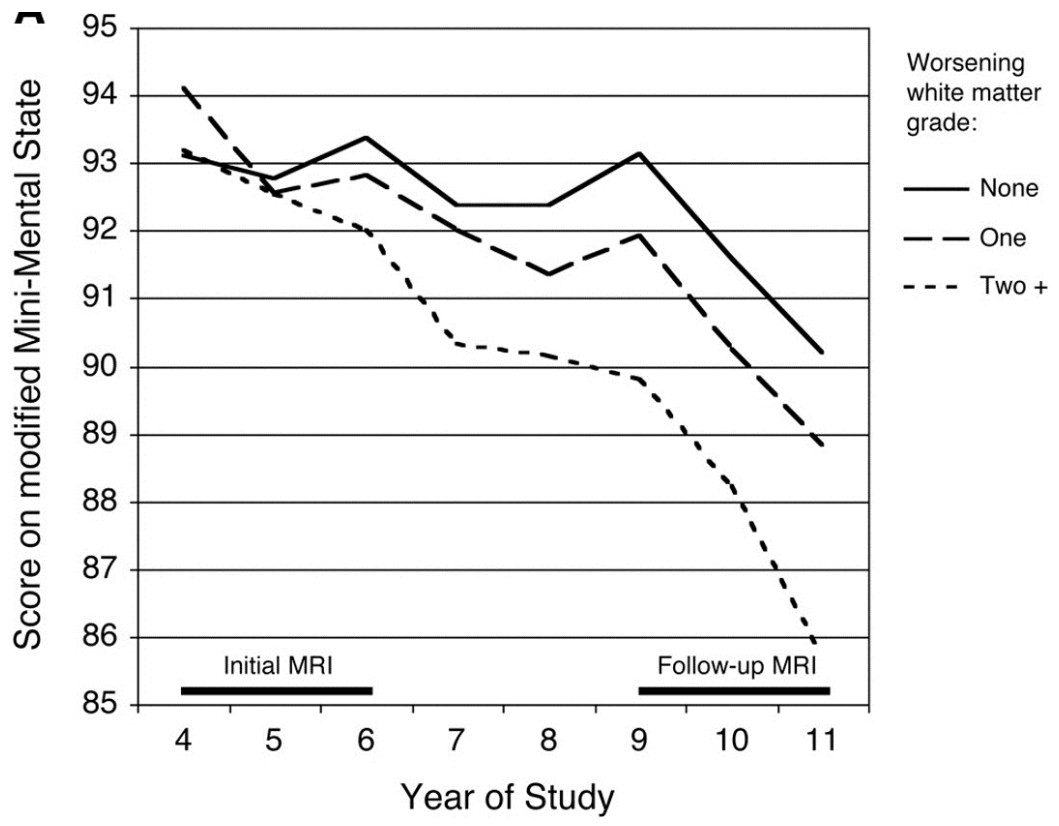

Fig. 3. Scores on modified Mini-Mental State Examination (vertical axis) for each year of study from initial to follow-up brain MRI scans (horizontal axis) by groups of participants (people aged 65 years and older) defined by worsening grade of white matter hyperintensity (three grade: None, grade One, and grade $\mathrm{Two}^{+}$).
Left ventricular systolic dysfunction:
Low left ventricular ejection fraction
Reduced $\mathrm{e}^{\prime}$, Increased E/e' ratio
Left ventricular diastolic dysfunction
Rhythm disturbance:
Increased BNP or N-terminal pro-BNP
Ankle-brachial index (ABI):
Development of atrial fibrillation
Low ABI
Carotid ultrasonography
Internal carotid artery stenosis

$\mathrm{e}^{\prime}$ : early diastolic mitral annular myocardial velocity by tissue Doppler echocardiography

E: early diastolic mitral flow velocity by pulse-wave Doppler echocardiography

Table 2. Cardiovascular indexes possibly to detect cognitive impairment

\section{Relationship between echocardiographic parameters and age}

Currently, LV diastolic function is evaluated based upon the following indices. Using pulsewave Doppler echocardiography, the ratio of E velocity and the late diastolic transmitral flow velocity (A): (E/A ratio), and early diastolic flow deceleration time are measured. By tissue Doppler echocardiography of mitral annular motion, $\mathrm{e}^{\prime}$ myocardial velocity can be evaluated. Also, diastolic function was evaluated by the diastolic Doppler index $\left(E / e^{\prime}\right)$, and this index is also useful to evaluate LV end-diastolic pressure or left atrial pressure in patients with heart failure with depressed or normal LV EF (Ommen et.al., 2000). 
Among the healthy subjects, the previous reports have evaluated the changes with age in various parameters. LV systolic function, obtained from LV EF by standard echocardiography or LV myocardial performance index using Doppler echocardiography, have shown minimum increments with age. However, LV diastolic function declined with age on echocardiographic parameters, i.e., E/A ratio and $\mathrm{e}^{\prime}$ velocity decreased, and E/e' ratio increased (Munagala et al., 2003). Furthermore, LV wall thickness and LV mass increased gradually with age, and suggested depression of LV myocardial compliance (Daimon et al., 2008).

In some reports discussing the relationship between cognitive impairment and cardiovascular dysfunction, LV diastolic function was depressed with the deterioration of cognitive function, which may be more progressive than that with aging alone (Hogg et al. ,2004). Furthermore, in patients with heart failure, cognitive function is depressed, but there is no clear data as to whether LV systolic function is depressed with the decline of cognitive function and its decline is improved with the correction of systolic dysfunction.

\section{Conclusion}

While age is the most significant contributing factor to the development of cognitive impairment, several epidemiological studies have elucidated that cardiovascular risk factors, i.e., hyperlipidemia, hypertension, smoking and diabetes contribute to the deterioration of cognitive function. Furthermore, LV systolic and diastolic dysfunction, have been reported to cause cognitive impairment, likely as a result of the development of poor cerebral perfusion. Brain white matter hyperintensitiy and thromboembolic stroke due to atherosclerotic factors and atrial fibrillation are also related to producing cognitive impairment. Therefore, doctors and medical professionals, who are involved with medical treatment for cerebrovascular and cardiovascular diseases must keep in mind that atherosclerotic disease processes are also related to the development of cognitive impairment and progression of dementia.

\section{References}

Blennow, K et al (2006). Alzheimer's disease. Lancet, Vol.368, No.9533, pp. 387-403.

Casserly, I. \& Topol, E. (2004) . Convergence of atherosclerosis and Alzheimer's disease: inflammation, cholesterol, and misfolded proteins. Lancet, Vol. 363, No.9514, pp. 1139-46.

Daimon M et al. (2008). Normal values of echocardiographic parameters in relation to age in a healthy Japanese population: The JAMP Study. CIrc J Vol.72, No.11, pp. 18591866.

Debette S \& Markus HS. (2010). The clinical importance of white matter hyperintensities on brain magnetic resonance imaging: Systemic review and meta-analysis. BMJ Vol.341, pp c3666 (on-line)

Gauthier, S et al (2006). Mild cognitive impairment. Lancet, Vol. 367: No. No.9518, pp.126270 .

Gunstad J et al. (2006). Relation of brain natriuretic peptide levels to cognitive dysfunction in adults $>55$ years of age with cardiovascular disease. Am J Cardiol Vol.98, No.4, pp. $538-40$. 
Hajjar I et al. (2011). Hypertension, white matter hyperintensities, and concurrent impairments in mobility, cognition, and mood: The cardiovascular health study. Circulation Vol. 123, No.8, pp. 858-865.

Hogg $\mathrm{K}$ et al. (2004). Heart failure with preserved left ventricular systolic function: Epidemiology, clinical characteristics, and prognosis. J Am Coll Cardiol Vol 43, No 3, pp.317-327

Jozwiak A et al. (2006) Association of atrial fibrillation and focal neurologic deficits with impaired cognitive function in hospitalized patients $\geq 65$ years of age. Am J Cardiol Vol. 98, No.9, pp.1238-41.

Knecht $S$ et al. (2008). Atrial fibrillation in stroke-free patients is associated with memory impairment and hippocampal atrophy. Eur Heart J Vol. 29, No.17, pp. 2125-2132.

Laurin D et al. (2007) Ankle-to-brachial index and dementia. Honolulu-Asia aging study. Circulation Vol. 116, No.20, pp. 2269-2274.

Longstreth WT Jr. et al. (2005). Incidence, manifestation, and predictors of worsening white matter on serial cranial magnetic resonance imaging in the elderly. The cardiovascular health study. Stroke 36, No. 1, pp56-61

Meguro K et al. (2002). Prevalence of dementia and dementing diseases in Japan: the Tajiri project. Arch Neurol. Vol. 59, No. 7, pp. 1109-1114

Munagala VK et al. (2003). Association of newer diastolic function parameters with age in healthy subjects: A population-based study. J Am Soc Echocardiogr Vol. 16, No.10, pp. 1049-56

Nash DT \& Fillit H. (2006). Cardiovascular disease risk factors and cognitive impairment. Am J Cariol, Vol. 97, No.8, pp.1262-65.

Ommen SR et.al (2000). Clinical utility of Doppler echocardiography and tissue Doppler imaging in the estimation of left ventricular filling pressures. A comparative simultaneous Doppler-catheterization study. Circulation Vol. 102, No.15, pp. 1788 94.

Romero JR et al. (2009). Carotid artery atherosclerosis, MRI indices of brain ischemia, aging, and cognitive impairment. The Framingham study. Stroke Vol. 40, No.5, pp.15901596

Saxby BK et al. (2008). Candesartan and cognitive decline in older patients with hypertension. Neurology Vol. 70, No.19 pt2, pp.1858-1866.

Suwa M \& Ito T (2009). Correlation between cognitive impairment and left ventricular diastolic dysfunction in patients with cardiovascular diseases. Int J Cardiol, Vol. 136, No. 3, pp. 351-354.

Welles CC et al. (2011). The CHADS2 score predicts ischemic stroke in the absence of atrial fibrillation among patients with coronary heart disease: Data from the Heart and Soul Study. ACC. 2011, J Am Coll Cardiol Vol.57, No.14, suppl S, E607.

Whitmer RA et al (2005). Midlife cardiovascular risk factors and risk of dementia in late life. Neurology, Vol.64, No.2, pp. 277-81.

Zuccala G et al. (2003). The effects of cognitive impairment on mortality among hospitalized patients with heart failure. Am J Med Vol. 115, No.2, pp. 98-103.

Zuccala G et al. (2005). Correlates of cognitive impairment among patients with heart failure: Results of a multicenter survey. Am J Med. Vol.118, No.5, pp. 496-502 


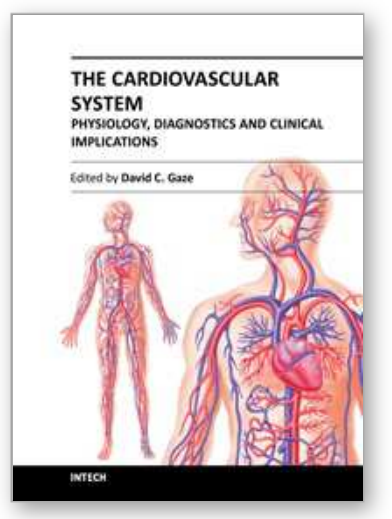

\author{
The Cardiovascular System - Physiology, Diagnostics and Clinical \\ Implications \\ Edited by Dr. David Gaze
}

ISBN 978-953-51-0534-3

Hard cover, 478 pages

Publisher InTech

Published online 25, April, 2012

Published in print edition April, 2012

The cardiovascular system includes the heart located centrally in the thorax and the vessels of the body which carry blood. The cardiovascular (or circulatory) system supplies oxygen from inspired air, via the lungs to the tissues around the body. It is also responsible for the removal of the waste product, carbon dioxide via air expired from the lungs. The cardiovascular system also transports nutrients such as electrolytes, amino acids, enzymes, hormones which are integral to cellular respiration, metabolism and immunity. This book is not meant to be an all encompassing text on cardiovascular physiology and pathology rather a selection of chapters from experts in the field who describe recent advances in basic and clinical sciences. As such, the text is divided into three main sections: Cardiovascular Physiology, Cardiovascular Diagnostics and lastly, Clinical Impact of Cardiovascular Physiology and Pathophysiology.

\title{
How to reference
}

In order to correctly reference this scholarly work, feel free to copy and paste the following:

Michihiro Suwa (2012). Cardiovascular and Cerebrovascular Problems in the Development of Cognitive Impairment: For Medical Professionals Involved in the Treatment of Atherosclerosis, The Cardiovascular System - Physiology, Diagnostics and Clinical Implications, Dr. David Gaze (Ed.), ISBN: 978-953-51-0534-3, InTech, Available from: http://www.intechopen.com/books/the-cardiovascular-system-physiology-diagnosticsand-clinical-implications/cardiac-function-in-depression-and-cognitive-decline

\section{INTECH}

open science | open minds

\author{
InTech Europe \\ University Campus STeP Ri \\ Slavka Krautzeka 83/A \\ 51000 Rijeka, Croatia \\ Phone: +385 (51) 770447 \\ Fax: +385 (51) 686166 \\ www.intechopen.com
}

\author{
InTech China \\ Unit 405, Office Block, Hotel Equatorial Shanghai \\ No.65, Yan An Road (West), Shanghai, 200040, China \\ 中国上海市延安西路65号上海国际贵都大饭店办公楼 405 单元 \\ Phone: +86-21-62489820 \\ Fax: $+86-21-62489821$
}


(C) 2012 The Author(s). Licensee IntechOpen. This is an open access article distributed under the terms of the Creative Commons Attribution 3.0 License, which permits unrestricted use, distribution, and reproduction in any medium, provided the original work is properly cited. 